\title{
Research Paper: Effectiveness of Cognitive Behavioral Therapy Training in Reducing Depression in Visually crosslark Impaired Male Students
}

Erfan Soleimani Sefat ${ }^{1}$, Seyyed Jalal Younesi ${ }^{* *}$, Asghar Dadkhah ${ }^{1}$, Mohammad Rostami $^{1}$

1. Department of Counseling, University of Social Welfare and Rehabilitation Sciences, Tehran, Iran.

Citation: Soleimani Sefat E, Younesi SJ, Dadkhah A, Rostami M. Effectiveness of Cognitive Behavioral Therapy Training in Reducing Depression in Visually Impaired Male Students. Iranian Rehabilitation Journal. 2017; 15(2):165-172. https://doi. org/10.18869/NRIP.IRJ.15.2.165

https://doi.org/10.18869/NRIP.IRJ.15.2.165

Article info:

Received: 12 Jan. 2017

Accepted: 27 Apr. 2017

Keywords:

Cognitive behavioral therapy, Depression, Male students, Visual impairment

\section{ABSTRACT}

Objectives: According to the prevalence of psychological problems, especially depression in people with visual impairment, this study aimed at investigating the effectiveness of group training of cognitive behavioral therapy in reducing depression in visually impaired male students.

Methods: This study employed a quasi-experimental design, with pre-test and post-test and control group. The study population included 30 students with visual impairment from high school and pre-university levels. The subjects studied at the Martyr Mohebi School in Tehran which is for visually impaired students. The subjects were selected by convenience sampling method and were assigned randomly to experimental and control groups (15 subjects in each group). The second version of the Beck Depression Inventory (BDI)-II was used as pre-test and post-test for both groups. The experimental group received 10 sessions (twice a week) of cognitive behavioral therapy while the control group followed their daily routine.

Results: Data analysis was done using statistical software SPSS (version 21). ANCOVA test was performed to examine differences between the two groups. The findings of this study indicate that cognitive-behavioral therapy training was significantly effective in reducing depressive symptoms of male students with visual impairment in the experimental group $(\mathrm{P}<0.01)$.

Discussion: The findings demonstrated that cognitive behavioral therapy was significantly effective in improving depression of male students with visual impairment in experimenta group. The group training needs to be adopted by medical practitioners on a cohort for validating its effectiveness on a larger scale. 


\section{Introduction}

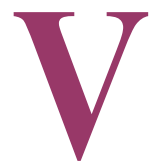

isual impairment, including blindness and low vision, is one of the most common disabilities. It has different definitions from the educational, medical, and legal point of views [1]. The WHO reported that about 285 million people worldwide have incurable visual impairment. Among them, about 39 million people are blind and 246 million have low vision. As per WHO's estimate, a person goes blind every 5 seconds globally. In Iran, there are about 124,165 blind people and 463,431 people with low vision [2].

The prevalence of visual impairment in Iran is moderate in comparison with other countries [3]. Based on the current trends and the lack of effective interventions, it is predicted that the number of visually impaired in the worldwide will increase to double by 2020 [4].Causes of blindness vary from country to country and even within a country [5]. The condition of blindness is also one of the most common sensory disabilities. Without any vision, the individual's perceptions of the world around him/her will be different, which can lead to emotional and social problems such as lack of compatibility, inactivity, lack of interest in others people, depression, and low self-concept [6].

Loss of vision is treated as a common symptom of old age; however, this complication is also prevalent in younger people [7]. In 2006, estimations showed that approximately 14 million visually-impaired Americans (12 years and older) experienced mental and physical challenges associated with loss of vision [8]. Many studies showed that during the developmental stage of children and adolescents with visual impairment, they continue becoming more vulnerable to life circumstances [9]. Low vision is associated with negative consequences such as limitations in day-to-day activities $[10,11]$, poor physical function [10], depressive symptoms [12-16], and low quality of life [17]. There is an internal relationship between sensory impairment, mental and social functioning, and communication [18].

It is well-documented that people with sensory impairment suffer from communication problems and reduced psychosocial functioning [18]. The results of Koenes and Karshmer's research showed that the incidence of depression among young visually impaired individuals is greater than that in normal sighted adolescents [19]. The results from a number of population-based and hospital-based studies in Asia, Europe, and North America indicated that people with visual impairment exhibited the highest rate of depression [20]. High rate of depression has also been marked in people with visual impairment in institutional environments [14]. Cyber Ravens believed that students with visual impairment caused due to sensory deprivation interacted less with their environment as compared to sighted people. Due to their low social skills and expressiveness, they gradually become introvert, depressed, and anxious [21]. In their study, Owsley and colleagues concluded that people with visual impairment are mainly presented with depression, social isolation, and other emotional problems such as frustration, fear, sadness, and inadequacy [22].

Childhood and adolescence depression is not a transient phenomenon that improves during the developmental stage. Factors contributing to recurrent depressive episodes, if neglected without any intervention, can subsequently lead to further inevitable complications [23]. One of the most effective treatments in this field is CognitiveBehavioral Therapy (CBT) [24]. CBT relies on the role of cognitive and behavioral processes in the formation of mental disorders and the use of empirical measures of cognitive and behavioral responses to change dysfunctional patterns [24]. Given the high prevalence of depression, psychotherapy cannot respond to these problems [25]. Therefore, we can use group therapy, instead of individual psychotherapy, as it is more advantageous in terms of cost, effectiveness, and duration of treatment. CBT is useful for people with visual impairment for reasons such as empirical evidence, its modified CBT method was made available for visually impaired individuals [26] and confirmation of its effectiveness for people with disabilities and chronic pain [27].

Successful use of CBT in studies involving adults with mild mental disabilities has been reported; these studies are mainly in the field of harassing behavior problems [28] and long-term psychotic symptoms [20]. Nadia and colleagues $[25,26]$ carried out cognitive-behavioral selfhelp programs to improve depressed mood and anxiety in people with hearing impairments and severe physical disorders that yielded positive results. Also, the results of Bison and colleagues' study [29] showed that cognitivebehavioral interventions reduced short-term symptoms of post-traumatic psychological distress in people with physical injuries.

Several studies [11-16] have stated high rates of depression in people with impaired vision. But only a few researches conducted on visually impaired people have accredited the role of psychological interventions in reducing depression in this group. Most of these studies are related to biomedical interventions, and the determi- 
nation of the impact of psychological interventions in improving the mental health of visually impaired individuals has been less attended. Individuals with visual impairment, as a member of the society, should take advantage and benefit from their ability to prevent and deal with a variety of mental disorders. Therefore, in this study, the effectiveness of cognitive behavioral group therapy in depression reduction is studied on male students with visual impairment.

\section{Methods}

This study employed a quasi-experimental design with pre-test and post-test and control group in which the effectiveness of an independent variable on a dependent variable was studied. Purposive sampling was used to select the sample. The study population included all high school and pre-university students with visual impairment in Tehran. The sample consisted of 30 students with visual impairment who were studying in The Martyr Mohebi School for the visually impaired in Tehran. According to scientific literature, a group having 6 to 14 or 8 to 15 members was ideal for carrying out group therapy sessions [30].

The sample was selected by purposive sampling method and was assigned randomly to experimental and control groups (15 subjects in each group). The second version of the Beck Depression Inventory (BDI)-II as pre-test and post-test was used for both groups. The experimental group received 10 sessions (twice a week) of CBT while the control group followed their daily routine. This self-report questionnaire was used as a tool for assessing depression-related cognition. The questionnaire obtained 21 items by observing signs of depressed patients. Each of these phrases is graded from 0 to 3 according to the severity of the patient's reported condition. A grade of 0 to 13 indicated minimal depression or being an ordinary individual [31].

Score 14 to 19 indicates mild depression, 20 to 28 indicates moderate depression, and scores of 29 to 63 show severe depression. The revised version of BDI compared to the first version has been found to be more consistent with DSM-IV and covers all elements of depression based on cognitive theory [32]. Reviews of Beck, Steer and the Caribbean stated that the second edition highlighted the presence and severity of depression in patients and normal population. They reported the reliability and internal consistency by Cronbach's alpha for patients to be 0.86 and 0.81 , respectively. In domestic studies conducted on the validity of this questionnaire, the values for parameters mentioned above were 0.70 to 0.90 , respectively [33].

The study was approved by the Ethics Committee of the University of Social Welfare and Rehabilitation Sciences and Exceptional Education in Tehran. Written consents from the parents were also obtained.

The study inclusion criteria were as follows: 1 . Students with no history of psychiatric hospitalization (based on the advice of cases); 2. No history of drug abuse (based on the counseling files); 3. Depression score between 14 and 28 (mild to moderate depression) (based on the Beck Depression Inventory); 4. Therapy or other methods are not effective; 5. Have willingness to participate in the study (via an interview in which they will be marked); and 6. IQ is in the range of 90-110 (the files of counseling in school). After selecting the experimental and control groups, the students in the experimental group were subjected to $10 \mathrm{CBT}$ sessions of 90 minutes each for over a period of 45 days (twice a week). According to research ethics, after psychological intervention and the implementation of the post-test, researcher held three sessions of CBT for the control group.

Framework and content of intervention used in this study was the Directory of specialists, "Overcoming the depression" [34] and a combination of group CBT sessions that has been designed to prevent recurrences of depression. The following training plan was followed. First session: Make an initial therapeutic alliance and an overview of the problem of depression. Second session: Recognition of depression and linking activities with depression. Third session: Overcoming behavioral syndrome. Fourth session: Meeting with avoidance. Fifth Session: Overcoming the emotion syndrome (linking of thinking and depression). Sixth session: Fighting negative thoughts (CBT - 3 questions). Seventh session: Discarding negative thoughts. Eighth session: Reforming the conflicting beliefs (meaning life). Ninth session: Preparing for the end of treatment. Tenth session: Review of group health plan, assessment of progress, reducing the possibility of recurrence, and saying goodbye.

After the intervention and the implementation of the post-test, data was analyzed via SPSS (version 21). After reviewing the assumptions of analysis of covariance test, this method was used for statistical analysis. Covariance test assumptions included: (a) Depression variable (post-test) and the covariate (depression pre-test) are normal; (b) The homogeneity of variance of variable depression (post-test) in both control and experimental groups is established; (c) Subjects were randomly as- 
signed to experimental and control groups. The assumptions of statistical method is homogeneity of variances using the Lyon test and Kolmogorov-Smirnov to review normality and total defaults as $(\mathrm{Sig}=0.386, \mathrm{~F}=0.849)$ and $(\mathrm{Sig}=0.869, \mathrm{Z}=0.569)$, respectively.

\section{Results}

Incomplete data from three students who completed the pretest but did not complete group therapy and five students who eventually completed group therapy but did not complete the posttest (four from control group and one from experimental group) were excluded due to lack of essential information. The final sample size reached to 22 subjects (11 in each group). The control and experimental findings of the demographic groups are presented in Table 1.

According to the data presented in Table 1, most of the students in both the experimental and control groups were aged 18 years and were mostly in the second grade of high school. Also, genetic diseases or congenital disorders in the early birth (up to 5 years) have been seen as the leading cause for visual impairment in many of the

Table 1. Demographic variables of male students with visual impairment

\begin{tabular}{|c|c|c|c|c|c|}
\hline \multirow{2}{*}{ Variable } & \multirow{2}{*}{ Components } & \multicolumn{2}{|c|}{ Experiment Groups } & \multicolumn{2}{|c|}{ Control Groups } \\
\hline & & Frequency & Percentage & Frequency & Percentage \\
\hline \multirow{7}{*}{ Age } & 16 & 1 & 9.1 & 3 & 27.3 \\
\hline & 17 & 3 & 27.3 & 3 & 27.3 \\
\hline & 18 & 4 & 36.4 & 4 & 36.4 \\
\hline & 19 & 1 & 9.1 & 1 & 9.1 \\
\hline & 20 & 1 & 9.1 & 0 & 0 \\
\hline & 22 & 1 & 9.1 & 0 & 0 \\
\hline & Total & 11 & 100 & 11 & 100 \\
\hline \multirow{5}{*}{ Academic year } & First grade of high school & 0 & 0 & 4 & 36.4 \\
\hline & Second grade of high school & 5 & 45.5 & 4 & 27.3 \\
\hline & Junior high school & 3 & 27.3 & 3 & 27.3 \\
\hline & Pre-university & 3 & 27.3 & 0 & 0 \\
\hline & Total & 11 & 100 & 11 & 100 \\
\hline \multirow{3}{*}{$\begin{array}{l}\text { Duration of visual } \\
\text { impairment }\end{array}$} & $1-5$ & 9 & 72.7 & 6 & 54.5 \\
\hline & $5-10$ & 3 & 27.3 & 5 & 45.5 \\
\hline & Total & 11 & 100 & 11 & 100 \\
\hline \multirow{3}{*}{$\begin{array}{l}\text { The cause of vi- } \\
\text { sual impairment }\end{array}$} & Genetic eye diseases or congenital disorders & 8 & 72.7 & 6 & 54.5 \\
\hline & Accidents leading to visual impairment & 3 & 27.3 & 5 & 45.5 \\
\hline & Total & 11 & 100 & 11 & 100 \\
\hline \multirow{3}{*}{$\begin{array}{l}\text { Type of visual } \\
\text { impairment }\end{array}$} & Progressive & 8 & 72.7 & 5 & 45.5 \\
\hline & Steady & 3 & 27.3 & 6 & 54.5 \\
\hline & Total & 11 & 100 & 11 & 100 \\
\hline
\end{tabular}


Table 2. The mean and standard deviation scores of experimental and control groups in the variable of depression

\begin{tabular}{ccccc}
\hline Variable & N & Groups & Mean & Standard Deviation \\
\hline \multirow{2}{*}{ Pre-test } & 11 & Experimental & 41.81 & 3.37 \\
& 11 & Control & 39.45 & 2.38 \\
Post-test & 11 & Experimental & 32.90 & 3.36 \\
& 11 & Control & 42.36 & 5 \\
\hline
\end{tabular}

Iranian Rehabilitation Journal

Table 3. Covariance test was used to compare post-test score depression for subjects in the experimental and control groups

\begin{tabular}{ccccc}
\hline Source Variance & $\begin{array}{c}\mathbf{d f} \\
\text { Depression }\end{array}$ & $\begin{array}{c}\text { MM } \\
\text { Depression }\end{array}$ & $\begin{array}{c}\mathbf{F} \\
\text { Depression }\end{array}$ & $\begin{array}{c}\mathbf{P} \\
\text { Depression }\end{array}$ \\
\hline Pre-test variable & 1 & 2.348 & 0.124 & 0.729 \\
\hline Group & 1 & 441.320 & 23.221 & 0.000 \\
\hline Error & 19 & 19.006 & & \\
\hline Total & 22 & & & \\
\hline
\end{tabular}

Ilranian Rehabilitation Journal

subjects. The resulting descriptive test results of the experimental and control groups are presented in Table 2.

The table shows a decrease in the mean of depression score in the pretest of experimental group compared to posttest of experimental group. The analytical results of the experiment and control groups are presented in Table 3. As seen in Table 3, the effect of group or intervention is statistically significant by removing and neutralizing the pre-test variable $(\mathrm{P}<0.01)$. Therefore, it can be concluded that the education component of cognitive behavioral therapy has been causing differences in the groups.

\section{Discussion}

This study aimed at investigating the effectiveness of the components of the cognitive behavioral group training therapy in reducing depression symptoms in visually impaired male students who were exposed to the independent variable (CBT) over a two-month period for ten 90-minute sessions. The findings of this study showed that CBT training played a crucial role in improving depression symptoms in male students with visual impairment in the experimental group. To neutralize the effect of depression in the pre-test score, it can be said that this difference is caused by the implementation of the independent variable in the experimental group. In other words, as CBT was conducted only in the experimental group and the control group did not receive any training, this program reduced depression scores of male students with visual impairment in the experimental group.

These findings are consistent with the results of other studies [20, 28, 35, 36]. It can be noted that childhood depression is not a transient phenomenon that can be improved during the developmental stage. In the etiology of depression, cognitive-behavioral patterns have their own place; depression is assumed in these patterns as a result of negative schema, learned helplessness, negative attribution style, lack of positive reinforcement, and lack of efficacy [37]. People with visual impairment face many challenges in their day-to-day life and are often deprived of basic abilities and skills, thus, becoming more vulnerable. Blindness is a serious condition that can affect mental balance and the entire organization of a visually impaired person. However, the negative attitude of visually impaired persons affects their personality in the organization more than their condition, and this also leads to depression and other psychological problems [38].

According to the model of Beck's cognitive therapy, the therapy is most effective when the therapist deals with the underlying assumptions in patients and replaces extreme thoughts (with intellectual distortions) with positive and logical thinking. In the present study, the therapist tried to get through proprietary techniques of 
cognitive therapy to correct the underlying assumption of some students with visual impairment that were dysfunctional. But in other cases, though people with visual impairment may not grow up with irrational thinking, but their health conditions and presumptions relating to their work performance can lead to negative thoughts and incompatible cognitions. Although their cognition is real, reasonable, and justified in terms of evidence, the truth is that some people with visual impairment have preoccupations. These preoccupations are harmful to people and increase stress and prevent positive response and intervention to do things that are useful for the individual. These preoccupations are often associated with difficult emotions, behaviors or physiological responses, and annoying problems [27].

Based on the study results, it can be concluded that CBT training reduces depression of male students with visual impairment. Also, based on the association of depression with other aspects of mental health, there is a need to pay attention to students with visual impairment in their present mental health conditions. Fundamental importance must be given to the use of psychological interventions, particularly the employed methods, by experts and psychologists to work with students with visual impairment. It seems that congenital visual impairment and acquired visual impairment have different effects on the psychological state of person. Therefore, it is recommended that these resolutions be considered in future research.

In this study, due to the small number of high school and pre-high school students at the Martyr Mohebi Schools, the researcher did not distinguish between students with congenital visual impairment and students who became visual impaired in later stage of their life. Another point is that because of cultural issues, the researcher was not able to do research on female students with visual impairment, these study was conducted only on male students with visual impairment Therefore is recommended on female students with visual impairment may also be performed.

\section{Conclusion}

In the present study, some people with visual impairment that yet was not compatible with their visual impairment and did not accept it (particularly those with visual impairment were 1 to 4 years) They believed that visual impairment is the worst thing that causes great discomfort, sadness, pleasure does not refer to many things, lack of activity, restrictions, and many other problems. This logically incompatible cognition, are real and the techniques used to deal with these cognitions differs from other techniques used to challenge irrational thoughts.
Therefore in Psychological trainings of These students, techniques such as self-advocacy training, problem solving, distraction and meditation, visualization, positive mental, planning for the future, stop thinking, and to involve family members in treatment should be used [27].

\section{Acknowledgments}

The authors would like to express their appreciation to the students who participated in this study. This research was extracted from the master's thesis of Mr. Erfan Soleimani Sefat in the Department of Counseling, University of Social Welfare and Rehabilitation Sciences.

\section{Conflict of Interest}

The author declared no conflicts of interest.

\section{References}

[1] Congdon NG, Friedman DS, Lietman T. Important causes of visual impairment in the world today. JAMA. 2003; 290(15):2057-60. doi: 10.1001/jama.290.15.2057

[2] Siamian H, Hassanzadeh M, Nooshinfard F, Hariri N [Health information needs of blind people in Iran (Persian)] Journal of Mazandaran University of Medical Sciences, 2012; 22(93):73-81

[3] Soori H, Ali JM, Nasrin R. Prevalence and causes of low vision and blindness in Tehran Province, Iran. Journal of the Pakistan Medical Association. 2011; 61(6):544-9. PMID: 22204207

[4] Siamian H, Hassanzadeh M, Nooshinfard F, Hariri N. [Health information needs of blind people in Iran (Persian)]. Journal of Mazandaran University of Medical Sciences. 2012; 22(93):73-81.

[5] Shrifian E, Estebsari F, Haghjou L, Nedjat S, Majdzadeh $\mathrm{S}$. [Determining behavioral preventive factors of blindness based on BASNEF model in the Chaharborj Village, city of Esfarayen (Persian)]. Iranian Journal of Health Education and Health Promotion. 2014; 2(3):186-98

[6] Maleki Tabar A, khodabakhshi koolaee a, Khoshkonesh A [Comparing the self-concept and social adjustment among blind and healthy male students (Persian)]. Zahedan Journal of Research in Medical Sciences. 2012; 13(10):33.

[7] Loprinzi PD, Codey K. Influence of visual acuity on anxiety, panic and depression disorders among young and middle age adults in the United States. Journal of Affective Disorders. 2014; 167:8-11. doi: 10.1016/j.jad.2014.05.052

[8] Vitale S, Cotch MF, Sperduto RD. Prevalence of visual impairment in the United States. JAMA. 2006; 295(18):2158-63. doi: 10.1001/jama.295.18.2158 
[9] Van Hasselt VB, Kazdin AE, Hersen M. Assessment of problem behavior in visually handicapped adolescents. Journal of Clinical Child Psychology. 1986; 15(2):134-41. doi: 10.1207/s15374424jccp1502_5

[10] Alma MA, Van der Mei SF, Melis-Dankers BJ, Van Tilburg TG, Groothoff JW, Suurmeijer TP. Participation of the elderly after vision loss. Disability and Rehabilitation. 2011; 33(1):63-72. doi: 10.3109/09638288.2010.488711

[11] Wallhagen MI, Strawbridge WJ, Shema SJ, Kurata J, Kaplan GA. Comparative impact of hearing and vision impairment on subsequent functioning. Journal of the American Geriatrics Society. 2001; 49(8):1086-92. doi: 10.1046/j.15325415.2001.49213.x

[12] Augustin A, Sahel J, Bandello F, Dardennes R, Maurel F, Negrini $C$, et al. Anxiety and depression prevalence rates in age-related macular degeneration. Investigative Ophthalmology and Visual Science. 2007; 48(4):1498. doi: 10.1167/ iovs.06-0761

[13] Burmedi D, Becker S, Heyl V, Wahl HW, Himmelsbach I. Emotional and social consequences of age-related low vision. Visual Impairment Research. 2002; 4(1):47-71. doi: 10.1076/vimr.4.1.47.15634

[14] Evans JR, Fletcher AE, Wormald RP. Depression and anxiety in visually impaired older people. Ophthalmology. 2007; 114(2):283-8. doi: 10.1016/j.ophtha.2006.10.006

[15] Hayman KJ, Kerse NM, La Grow SJ, Wouldes T, Robertson MC, Campbell AJ. Depression in older people: Visual impairment and subjective ratings of health. Optometry \& Vision Science. 2007; 84(11):1024-30. doi: 10.1097/ opx.0b013e318157a6b1

[16] Horowitz A, Reinhardt JP, Kennedy GJ. Major and subthreshold depression among older adults seeking vision rehabilitation services. American Journal of Geriatric Psychiatry. 2005; 13(3):180-7. doi: 10.1097/00019442-20050300000002

[17] La Grow S, Alpass F, Stephens C, Towers A. Factors affecting perceived quality of life of older persons with selfreported visual disability. Quality of Life Research. 2010; 20(3):407-13. doi: 10.1007/s11136-010-9758-6

[18] Soleimani-Sefat E, Rostami M, Amani S, Movallali G. The needs and problems of students with visual impairment. Journal of Social Sciences and Humanity Studies. 2016; 2(2): 8-16.

[19] Koenes SG, Karshmer JF. Depression: A comparison study between blind and sighted adolescents. Issues in Mental Health Nursing. 2000; 21(3):269-79. doi: 10.1080/016128400248086

[20] Evans JR1, Fletcher AE, Wormald RP. Depression and anxiety in visually impaired older people. Ophthalmology. 2007; 114(2):283-8. doi: 10.1016/j.ophtha.2006.10.006

[21] Ravens-Sieberer U, Morfeld M, Stein R, Jessop DJ, Bullinger $M$, Thyen $U$. [The testing and validation of the German version of the impact on family scale in families with children with disabilities (German)]. Psychotherapie, Psychosomatik, Medizinische Psychologie. 2000; 51(9-10):38493. doi: $10.1055 / \mathrm{s}-2001-16899$

[22] Owsley C, McGwin Jr G, Scilley K, Dreer LE, Bray CR, Mason III JO. Focus groups with persons who have age-related macular degeneration: Emotional issues. Rehabilitation Psychology. 2006; 51(1):23-9. doi: 10.1037/0090-5550.51.1.23

[23] Power M. CBT for depression: The Wiley-Blackwell handbook of mood disorders. Hoboken: Wiley-Blackwell; 2013.

[24] Zarb J. Cognitive behavioural assessment and therapy with adolescents. Abingdon: Routledge; 2014.

[25] Talaei A, Kimiaei SA, Borhani Moghani M, Moharreri F, Talaei A, Khanghaei R. [Effectiveness of group cognitive behavioral therapy on depression in infertile women (Persian)]. The Iranian Journal of Obstetrics, Gynecology and Infertility. 2014; 17(94):1-9.

[26] Utoyo DB. Modifying cognitive-behavioral therapy for a depressed older adult with partial sight: A case report. Gerontology and geriatric medicine. 2015; 1:1-3. doi: $10.1177 / 2333721415585432$

[27] Taylor RR, Renee R. Cognitive behavioral therapy for chronic illness and disability. Berlin: Springer; 2006.

[28] Shahni R, Shairi MR, Asghari Moghaddam MA. Appointment the effectiveness of cognitive-behavioral treatment of pain on increasing of self-efficacy in patients with chronic pain. Procedia-Social and Behavioral Sciences. 2013; 84:2259. doi: 10.1016/j.sbspro.2013.06.539

[29] Bisson JI, Shepherd JP, Joy D, Probert R, Newcombe RG. Early cognitive-behavioural therapy for post-traumatic stress symptoms after physical injury: Randomised. British Journal of Psychiatry. 2004; 184(1):63-9. doi: 10.1192/ bjp.184.1.63

[30] Corey MS, Corey G, Corey C. Groups: Process and practice. Boston: Cengage Learning; 2013.

[31] Stefan-Dabson K, Mohammadkhani P, Massah-Choulabi O. [Psychometrics characteristic of Beck Depression Inventory-II in patients with magor depressive disorder (Persian)]. Archives of Rehabilitation. 2007; 8:80-86.

[32] Aben I, Verhey F, Lousberg R, Lodder J, Honig A. Validity of the beck depression inventory, hospital anxiety and depression scale, SCL-90, and Hamilton depression rating scale as screening instruments for depression in stroke patients. Psychosomatics. 2002; 43(5):386-93. doi: 10.1176/ appi.psy.43.5.386

[33] Azkhosh M. Application of psychological tests and clinical diagnosis. Tehran: Ravan Publication; 2009.

[34] Emery G. Overcoming depression: Therapist Protocol. Oakland: New Harbinger Publications; 2000

[35] Hyun MS, Chung HIC, Lee YJ. The effect of cognitive-behavioral group therapy on the self-esteem, depression, and self-efficacy of runaway adolescents in a shelter in South Korea. Applied Nursing Research. 2005; 18(3):160-6. doi 10.1016/j.apnr.2004.07.006

[36] Nash VR, Ponto J, Townsend C, Nelson P, Bretz MN. Cognitive behavioral therapy, self-efficacy, and depression in persons with chronic pain. Pain Management Nursing. 2013; 14(4):236-43. doi: 10.1016/j.pmn.2012.02.006

[37] Tahmassian K, Anari A. [The relation between domains of self-efficacy and depression in adolescence (Persian)] Journal of Applied Psychology. 2009; 3(1):83-93. 
[38] Poorseyed SR, Habibollahi S, Faramarzi S. [Effectiveness of life skills educational program on blind and low-vision university students compatibility (Persian)]. Education Strategies in Medical Sciences. 2010; 3(1):3-4. 